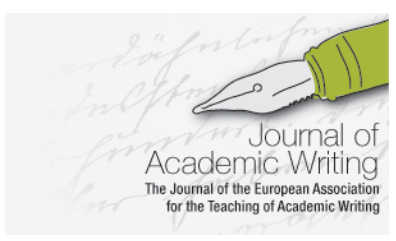

Journal of Academic Writing Vol. 10 No 1 WINTER 2020, pages 75-86 https://doi.org/10.18552/joaw.v10i1.598

\title{
Towards Nuanced Understandings of the Identities of EAL Doctoral Student Writers
}

\author{
Shem Macdonald \\ La Trobe University, Melbourne, Australia \\ Britta Schneider \\ Monash University, Melbourne, Australia
}

\begin{abstract}
The construct of identity in the space of English as an Additional Language (EAL) Higher Degree by Research (HDR) writing has been widely researched with studies exploring students' identities as constructed through and in the process of writing. However, these studies are often presented in ways that focus on the challenges the writers face, citing language barriers and cultural differences and ascribing these students "closed subject positions" with "limited ways of talking about themselves" (Koehne, 2005, p. 118). In response to such deficit views, various studies have explored the multiple and varied identities of HDR EAL students as evident in their written reflections and other work, offering a wider range of views. We argue that there is a need for additional nuanced views of these student identities and how they are formed. In this paper we demonstrate how these can be gained by examining student identities as they emerge through spoken interaction. Applying a sociocultural linguistic framework that understands identities as emerging, situationally and relationally dependent (Bucholtz \& Hall, 2005), we report how two students formed identities for themselves by talking to us about their experiences of writing using EAL. Our analysis provides nuanced understandings of the multiple identities of EAL HDR students that move beyond the deficit ones we were, and still are, frequently hearing in institutional discourses and demonstrates how the application of this framework can help articulate richness, variety and resourcefulness, and challenge essentialised identities of EAL doctoral student writers.
\end{abstract}

\section{Introduction}

The construct of identity and why it matters for doctoral writing has been addressed by a range of researchers. Studies of student writers using English as an Additional Language (EAL) ${ }^{1}$ for their doctoral studies often focus on the challenges they face (Chang, 2011, p. 14). Such discourses cite language barriers and cultural differences and ascribe these students "closed subject positions" with "limited ways of talking about themselves" (Koehne, 2005, p. 118). A number of studies have explored student identities in relation to academic voice and why students may or may not use English academic discourse features in their writing (Botelho de Magalhães et al., 2019; Canagarajah, 2015; Hyland, 2012; Ivanič, 1998; Tardy, 2016; Thompson et al., 2016). Others have examined the impact on identity formation of giving and receiving feedback on students' writing (Aitchison et al., 2012; Cotterall, 2011; Kamler \& Thompson, 2006; Leki, 2006; Morton et al., 2014). There is a consistency of views that doctoral writing can become a site of tension for multilingual students and their supervisors (Aitchison et al., 2012; Starke-Meyerring et al., 2014; Tran et al., 2017) with some students even experiencing loss of identity (Cotterall, 2015; Ingleton \& Cadman, 2002). To understand these

${ }^{1}$ Throughout this paper, we will use the term English as an additional language - EAL - to describe the kinds of backgrounds and uses of English of speakers who may have English as a foreign language, or English as a second, third etc. language. 
prevailing deficit perceptions, some researchers have explored the distribution of personal, social and institutional power in the student-supervisor relationship and its lingering impact on identity formation (Badenhorst et al., 2015; Casanave, 2010; Chang, 2011; Cotterall, 2013, 2015; Manathunga, 2007; Tran et al., 2017).

Different approaches have been taken to explore the identities that students experience during Higher Degree by Research (HDR) ${ }^{2}$ processes. A number of researchers have analysed various written artefacts. For example, Ivanič (1998) used students' writing to create case studies that revealed the many discursive "selves" students realize in their texts. Casanave (2002, p. 11) used literacy autobiographies to show the game-like nature of student writer identities that are "in a state of flux", and "inextricably linked to writing-related practices". Phan (2009, p. 143) analysed written notes from conversations with her PhD student and the student's journal entries to theorise about her approach to "critical EAP and Thirdspace pedagogy". Another example is that of Soong, Tran and Hiep (2015, p. 435), who described how their autobiographical and reflective writing helped them to understand their own plural and changing doctoral candidate identities. They indexed themselves as "becoming an 'AsianAustralian' migrant and doctoral student ... shifting from being an 'expert' in teacher education to becoming an international doctoral student", or having "plural identities as a mother, an intercultural learner and a doctoral student" (2015, p. 436). A further study by Tardy examined graduate research students' PowerPoint slides, and suggests that by "[e]xtending our study of identity and writing to both verbal and visual modes of expression allows for a richer understanding of the various identities that multilingual writers bring to their texts" (2005, p. 321). These studies all contribute to a broader understanding of HDR EAL writer identities, in particular, by showing that they vary widely both across and within individuals. It is also apparent in much of this research that these identities are not fixed but are emergent, situational and relationally dependent and are being formed at different times for different purposes.

To further our understanding of these processes, our own study examines these identity formation processes, not through written texts, but as they take place moment to moment during spoken interactions with EAL HDR student writers. Our aim is firstly, to respond to the call for further in-depth exploration of EAL HDR student identities (Casanave, 2012), and secondly, to demonstrate how nuanced understandings of the identities of EAL doctoral student writers can be gained as they emerge through spoken interaction. We explore in detail this emergence by analysing the identity formations that occurred during our interviews with EAL HDR students. To do this, we apply a sociocultural linguistic framework to our interview data that allows us to approach doctoral students' identities as they emerge from moment to moment in interactions in their specific and local discourse contexts. We explain the framework in more detail below, but before doing that, we provide some context for this study.

\section{Understanding EAL HDR student identities}

Our interest in gaining a better understanding of EAL HDR student identities stems from our previous work as Academic Language and Learning lecturers at an Australian university where one of our responsibilities was to contribute to the development of these students' academic writing. In this work, through individual consultations, we were hearing a range of stories about how these students felt about what they were doing, and the changes and challenges they faced. It was not uncommon for these students to express deficit discourses about themselves as researchers and writers and this was often connected with their use of English. They would frequently open consultations by telling us that their supervisor had sent them to "fix up their grammar" or that their "English expression was bad". However, after working with these students over several sessions, it was evident that their skills with academic (and social) English varied widely, each presenting different characteristics, many strengths as well as different areas that we might focus on to help them use more standard and/or effective forms of

\footnotetext{
${ }^{2}$ We use the term higher degree by research (HDR) to describe doctoral candidates. However, we acknowledge that the term is also used to refer to masters candidates who are writing a research thesis.
} 
academic English. Through talking with the students about their writing and research projects we gained glimpses of the multiple ways they understood themselves. These experiences prompted us to wonder why discourses about their deficit identities seemed to dominate at least the initial conversations we had with the students, but were also salient when talking with some academic staff.

In our roles we also interacted with the academic supervisors. Sometimes, they contacted us directly asking us to work with their students. Other times, we might have approached them in workshops when we publicised the support we provided. The ways they described what their students needed varied. Some supervisors felt that their students had not improved much despite having been given lots of feedback, yet others worried when their students' work had visibly improved wondering, whether it was the students' own work. Writing issues identified by supervisors were often framed as a result of the student's poor command of English or limited ways of critical thinking. Other issues sometimes emerged that were more to do with the supervisors' concerns about the students' orientation to, and participation in, the broader academic research culture of the university, and even their engagement in social events with other students from the same background.

These contacts prompted us to design a research project to gain nuanced understandings of the identities among HDR students using EAL. We wanted to learn more about their experiences to uncover whether, and if so, how the positioning of EAL HDR students as researchers and writers might be framed as a problem beyond the typical challenges facing most HDR writers (e.g. writer's block, achieving clarity in writing, finding time to write, etc). We had the impression that the discourses about EAL student identities that we were hearing tended to be dominated by deficit views of what they could not yet do or even were refusing to try to learn how to do.

To explore these issues further, we invited students and supervisors to take part in an interview about their experiences with using EAL for their higher degree research, or of supervising students who use EAL for their higher degree research. In this article, we do not report on the findings from the interviews with the supervisors, but narrow our focus to explore how two of the students, during our conversations with them, formed identities for themselves that were complex and multi-layered. Our application of a framework allowed us to gain more nuanced understandings of their identities than we were initially seeing. These understandings also were different to those discussed in the literature in the ways they emerged from moment to moment in spoken interaction.

\section{Theoretical Framework}

To explore how these students formed identities for themselves and others when describing their experiences of writing, we use a theoretical framework developed by Bucholtz and Hall (2005), who understand identities as emerging through interaction, as situationally, intersubjectively, and relationally dependent, and as constructed via a range of positioning and indexical processes. The framework's relevance to our study is its capacity "to describe an identity that has been unrecognized or misrecognized by researchers or cultural members" (p. 160) and "to add greater nuance to the conceptualization of identity and its construction" by revealing the "instability of identity categories from moment to moment" (p. 161).

Bucholtz and Hall draw together insights from research from a variety of fields to create a framework consisting of five principles that they view as "fundamental to the study of identity" (2005, p. 586). They present these as "the comprehensive toolkit already available to [scholars] for analyzing identity as a centrally linguistic phenomenon" (2005, p. 586.) The principles are: emergence, positionality, indexicality, relationality and partialness. Bucholtz and Hall and other researchers have used each of these principles, separately and in different combinations to undertake these kinds of analyses. In the following, we briefly explain the five principles.

The first principle is the principle of emergence and can be described as the umbrella principle of the framework. It views identity "as the emergent product rather than the pre-existing source 
of linguistic and other semiotic practices and therefore as fundamentally a social and cultural phenomenon" (2005, p. 588). This principle can be applied to all our examples in the way that aspects of our participants' identities became apparent or emerged only through the interactions we had with them and were not characteristics that might be described as fixed and/or clearly evident in other contact with them. For this reason, we only touch on emergence in our analyses below. The principle of indexicality concerns the multiple ways in which speakers use both overt and implied referential identity categories and labels within an interaction (2005, p. 594). The principle of positionality captures the way identities can encompass "temporary and interactionally specific stances and participant roles" (2005, p. 592). The principle of relationality is considered the "heart" of the framework (2005, p. 587) because it exposes identity as an intersubjectively negotiated phenomenon. This principle is useful for understanding how speakers construct identities in relation to "other available identity positions and other social actors" (2005, p. 598). Within an interaction, speakers create relationships of "adequation and distinction", "authentication and denaturalization", and "authorization and illegitimation" (2005, pp. 599-605). While these separate relational concepts facilitate the elucidation of identities as constituted through language, they "typically work in conjunction with one another" (2005, p. 599). The fifth principle is that of partialness. With this, Bucholtz and Hall emphasise the vast number of ways that "identity exceeds the individual self" (2005, p. 605). They claim that the construction of identity may be partly deliberate, habitual, a result of interactional negotiation, or due to other people's perceptions.

This framework has been used in a range of contexts to study how people use language to form identities for themselves. For example, Mango (2012) looked at Arab American women's identities and how they emerge during moment-to-moment spoken interaction; Rajadurai (2010) looked at how adult L2 learners of English language in Malaysia negotiate identities and struggle for participation, legitimacy and acceptance. Shenk used parts of the framework to explain how members of a bilingual Mexican American friendship group engage in "authenticating discourse" (2007, p. 194) and act to position themselves as authentic and the others as inauthentic. However, to our knowledge, this framework has not been used to advance our understanding of the identities of HDR EAL writers and how they form identities through their spoken interaction. Therefore, our study both broadens the application of this framework while providing an opportunity to gain more nuanced understandings of members of this cohort.

\section{Methodology}

We adopted a qualitative study design to explore the experiences and views of HDR EAL students and university lecturers who were supervising HDR EAL students. After obtaining ethics approval from the university, we published a call on the university's HDR email list asking students and supervisors interested in our research topic to come forward. Within days we received over 20 expressions of interest, which was more than we had expected. From these, we conducted 14 semi-structured interviews of between 40-60 minutes; five with HDR students and nine with HDR supervisors. The interview questions for students focused on their use of English, their additional language, for their research and writing. Of the five students that we interviewed, three were women, and two were men. They came from a range of disciplines: Law, Politics, Second Language Acquisition, and Sports Science.

We audio recorded and transcribed all the interviews. We had each transcription checked for accuracy by a colleague. The data analysis took place in a step-wise process. First, we examined the identity framework by Bucholtz and Hall (2005) comparing and clarifying our individual understandings of the five principles. We then went through the interviews, reading the transcripts and listening to the recordings as often as necessary, using Bucholtz and Hall's five principles to identify examples of where the principles could be applied to understand how the speakers were forming aspects of their identities. To ensure reliability, we did these analyses separately after which we compared and discussed our findings. Our comparison yielded many examples in each interview where we both had applied the same principles for interpreting how identities were being formed. 


\section{Results}

For reasons of space, we present excerpts from interviews with two students (one female and one male) along with our analysis of them using the principles from Bucholtz and Hall's framework. Pseudonyms are used and references to specific disciplines or institutions have been changed so as to de-identify participants. We acknowledge that these two short examples do not convey all aspects of these students' identities. Further, we do not, and cannot claim that these students and our analysis of their identities are representative of all HDR students or even of all five students we interviewed for this study. However, we present these as examples that are useful in the ways they allow us to see how a nuanced understanding of these HDR EAL students' identities can be gained through an analysis of their spoken interactions.

\section{Paula}

Our first student is Paula. At the time of the interview, she is 37 years old and in the second year of her PhD in Social Sciences. Her first language is Bahasa Indonesian. The interviewer knows the student from one-on-one consultations. The interview with Paula was conducted in a meeting room at the university. The interviewer asks Paula how she negotiates the different styles of her two supervisors, one accepting of non-standard forms of language, the other wanting her to conform to the rhetorical conventions of English academic writing. In her response, Paula explains:

I tend to take a pragmatic approach with it like ... a very narrow pragmatic approach because I'm thinking, ok in the end who is going to read my dissertation, it's the two examiners. These two examiners, they function in English zone, English way of thinking. I think their suggestion will [make] easier my way to communicate with these two examiners. Yeah ... as long as [it is] not changing the message that I like to convey.

Paula's response suggests she conforms with the supervisor who is critical of her EAL writing and prescriptive in his editing of her work. Simultaneously to overtly indexing herself as pragmatic, she creates a relation of distinction between herself and the potential examiners of her thesis "who function in English zone and English way of thinking". By differentiating herself from the examiners she presents herself as an EAL HDR writer who possesses ways of functioning and thinking distinct from someone who thinks and writes in English only. By saying that she will follow her supervisor's suggestions because it will make it easier for her to communicate with the examiners, she emerges as a writer who has an identity that is shaped to some extent by the views and expectations of others. However, at the same time, she maintains her own authority saying that she will only accept the changes to her writing if they do not change the meaning of her message. The principle of relationality, specifically the relation of distinction, reveals Paula's identity as more complex than simply conforming to the supervisor's language choices.

The next excerpt from a little later in the interview, shows how Paula forms an identity position for herself which can be understood using the principle of partialness: "Any given construction of identity may be ... in part an outcome of others' perceptions and representations" (Bucholtz \& Hall, 2005, p. 606). This is evident in the way Paula reports the perceptions of her, of one of her former lecturers. In this excerpt, Paula recalls a corridor conversation with this lecturer who, Paula reports, sees her as a competent thinker and writer based on the lecturer's experiences speaking with Paula:

I remember in an informal conversation she said like, I'm not sure whether she used the term lucky, she said something like "oh it's good that that we met before and I know your speaking style so that I can understand your writing better" ... yeah so she said that "probably if we never ... in contact before I never have an experience of having like ... a verbal conversation I might look at your writing differently"

Paula, in reporting what this lecturer said, presents to us an identity of herself as a genuine writer with something worthwhile to contribute even though her written expression might not conform to this lecturer's expectations. The principle of relationality, specifically, the relation of 
authentication, allows us to see this. Paula reports being acknowledged as an authentic writer by a person in a position of higher authority - and someone who knows her well.

In the third excerpt below, the principles help us to see "structural and institutional aspects of identity formation" in Paula's utterance, captured by the relations of authorization and illegitimation (Bucholtz \& Hall, 2005, p. 603). While further exploring the tensions between writing that conforms to the rhetorical conventions expected by her supervisor and future examiners, and her writing in English that reflects ways of writing in her first language, Paula evokes the expected institutional roles of EAL students and those of their lecturers:

I can't expect every lecturer here to have understanding. No I can't expect that but if the error is two-sided like students try to master English and at the same time staff ... because they declare themselves as ... I mean because they formally open themselves to have international students so it's sort of like ... I don't know normative or moral obligations to also try to understand the language difference.

While Paula acknowledges that she does not expect all her lecturers to understand her writing in English if it follows the writing style of her first language, she also argues that both parties, students and staff, should meet half way. In this interaction, the principles of relationality, specifically, illegitimation and authorization, allow us to see the ways Paula forms identities for herself and others. While acknowledging the need for students to work to master English, she illegitimates the identities of students as being the people who need to make all the compromises. At the same time, she affirms the lecturers as having identities bound by "normative and moral obligations" authorizing them with the imperative of understanding the "language difference" as part of the situation of international students.

Applying the principles of indexicality, partialness and relationality to these excerpts from the interview with Paula allows a nuanced articulation of the processes involved in the formation of her identities and how we might understand them.

\section{Farzad}

Our second student is Farzad, who is 32 years old at the time of the interview and in the third and final year of a PhD in Sports Sciences. Farzad's first language is Farsi. He responded to our call for participants without having had any prior interactions with us or our department. The interview with Farzad was conducted in a meeting room on campus. Farzad introduces himself by saying:

I've been here in Australia for more than eight years so my situation might be a bit different to other international students that you are going to interview.

We gain an understanding of how Farzad constructs his identity using the principle of relationality specifically, the relation of distinction (difference). This applies where he explains having lived in Australia for more than eight years which, he suggests, makes his situation different to that of other international students. While he does not immediately explain why he opens the interview making this distinction, he adds that he has also completed his Master's degree in Australia and this serves to establish him as someone who is not new to the practices of academic research and writing in an Australian university.

Next when telling us about his response to the feedback from his supervisors on his writing some nuanced identities emerge. He says:

Writing is very different to what I'm used to. It brings its own challenges. Sometimes you know I write something and to myself I think "yeah it makes perfect sense" but when I get the feedback I see the mistakes I've made or sometimes I receive feedback and I don't even understand why [my supervisors] are asking me to clarify this because it is making perfect sense to me. It can be challenging and sometimes frustrating. Actually I received feedback from my supervisor just a couple of days ago and there are so many of these things that I couldn't understand why he is asking me to explain this, why he is saying this is vague because it was perfectly clear to me. 


\begin{abstract}
When I receive the feedback from my supervisor I realize ... I've made ... so many mistakes and sometimes ... even when I have their feedback, I still can't understand where l've gone wrong ... and why did they say ... yeah "This sentence doesn't make sense or this word is vague ... you need to clear this, you need to talk about this more" and yeah to myself it's a bit frustrating I think, you know, it's making per perfect sense, you know, I cannot write two sentences just to explain one word, you know, to to me I I think if I explain ... these sentences or words too much, the reader can get frustrated and think, you know, "Are you assuming I am an idiot", heh heh, "explaining these simple things?" so um yeah, it has gone both ways, and sometimes l've explained something and my supervisor getting back to me, you know, "You have said this why are you saying this again?" ... so it can get very frustrating at times
\end{abstract}

The positionality principle states that "identity emerges in discourse through the temporary roles and orientations assumed by participants" (Bucholtz \& Hall, 2005, p. 591). Farzad does this when speaking through adopting the voices of others. This is achieved not only through the words that are borrowed or quoted, but also through the way he adopts the roles and orientations of others as revealed in the audio-recording through the obvious changes in his voice quality and his use of intonation. The parts of the excerpt given in italics mark these voices and roles of his writing or thinking self, his supervisors, an imagined reader, and then a supervisor again. These are nuanced identity categories, temporary and multiple, and they emerge through his interactions with us during the interview.

When asked how he negotiates the feedback on his writing, Farzad explains:

Previously I used to just take it as "yes this is wrong and I have to change it". I used to just do that and just fix it even though l'd think, you know, "I wasn't wrong and I can't understand where l've gone wrong." I used to just change it but in the last draft I got so frustrated, and yesterday I had a meeting with my supervisor where I kind of vented out, heh heh, and told them "this is the situation and this is how I feel sometimes with these things" and now l'm supposed to change this second draft that I've submitted and submit a third draft after I make these changes. I haven't talked about every single one of those things but I am going to actually clarify them one by one probably. Because it's towards the beginning of writing my thesis now ... and I want to get it right at the beginning so we don't have to have these issues all the time when I submit something.

Applying again the principle of relationality to this excerpt reveals how Farzad constructs a legitimate writer identity for himself by creating a relation of authorization in regard to the institutionalised roles of supervisor and student writer. In response to the feedback he receives on his writing, he subverts the traditional or expected student role, by affirming greater agency in the process of writing. Previously, while privately holding on to his belief that he was not wrong and what he wrote made perfect sense, he just did as he was told. This time he tells us about how, for the first time, he vented his frustration and explained to his supervisors how their feedback made him feel. He is not allowing the copious and detailed feedback he receives on his writing from his supervisors make him feel delegitimized as a writer. Instead, he describes his new position where he feels ready to ask his supervisors to clarify each instance of where he cannot understand what he has done wrong. He will request more immediate and explicit and oral feedback now than before. He no longer feels obliged to conform to the previously established roles of his supervision and writing practices whereby his supervisors point out his mistakes and he, as dutiful student, corrects them unquestioningly.

\title{
Discussion
}

Approaching the identities of these two EAL HDR student writers through the exposition of the principles of emergence, indexicality, partialness, relationality and positionality in their spoken interactions with us, we were able to identify identities that went beyond the narrow focus we encountered in our institution on the challenges these writers face or of presenting them as having closed subject positions or presenting mainly deficit perceptions of them. By applying 
principles from the framework to what Paula is telling us, we can appreciate her achievements in creating identities that do not position her as inferior or lacking. As the interview progresses, Paula authenticates herself as a legitimate EAL writer by means of another lecturer's authority. Additionally, she rejects the imperative to master English, drawing on the authority of the university and its lecturers to work towards understanding her habitual ways of thinking, speaking and writing.

The principles also allow us to more fully understand this student's articulation of her position towards the internationalisation of higher education. Paula challenges the understanding of internationalisation by Australian universities as "internationalising English-only pedagogies" (Singh \& Han, 2017, p. 52) and very subtly opens the in-between space for EAL students in HDR supervision. Her personal struggle to become an acknowledged researcher and writer becomes political and one that should be taken up by universities, teachers of academic writing and supervisors when considering pedagogies for EAL HDR education (Ai, 2017; Singh \& Han, 2017).

Applying the different principles to the excerpts from an interview with the second student we report on in this paper, Farzad, shows a person who has spent a considerable part of his young adult life in Australia and who is familiar with the practices at this particular English speaking university. While talking about his experiences with writing, he describes the internal conversations he has with himself, his imagined reader and his supervisors. In his interactions with us he constructs identities for himself that show different degrees of compliance and autonomy with regard to his own writing and his relationship with his supervisors. It is as if in the interview with us, Farzad is forming for himself a new way of negotiating his writing processes in the supervision space. While we do not know if he followed through with what he told us in the interview, the point we are interested in here is how we can better understand his experiences through the ways he forms his multiple identities as an EAL HDR writer in the brief moments of the interview.

\section{Conclusion}

In institutional discourses, EAL HDR writers are often described as people belonging to more or less fixed categories such as international and students. This conjures images of somewhat stable social, educational or professional identities, for example, doctoral students as relatively young and independent, from different cultural and educational backgrounds, aspiring to a research career but lacking the linguistic sophistication or cultural capital. Such images foster certain expectations and pre-conceived ideas about the knowledge base, language, and writing abilities of doctoral students.

Although a considerable body of research has looked at identity formation linked to the writing of EAL HDR students, a number of these have focused on the linguistic and discursive choices in their texts (Hyland, 2012; Ivanič, 1998; Tardy, 2016; Thompson et al., 2016) or on what the students say about the feedback they receive on their writing (Aitchison et al., 2012; Cotterall, 2011; Kamler \& Thompson, 2006; Leki, 2006; Morton et al., 2014). Studies from a dialogic perspective tend to view these identities as evolving over a longer period of time (e.g. Casanave, 2002; Tardy, 2005; Phan, 2009; Soong, et al., 2015). Our approach has been different by focusing on how students talk and construct identities in spoken, moment-tomoment, brief interactions. By engaging the principles of identity formation from Bucholtz and Hall's framework, we show how we could identify identities that the students create for themselves when talking to us. By applying the principles we notice how quickly the speakers switched between the layers of at times contested and changing identities. In our moment-tomoment analysis of the interview data we start to see how these formation processes unfold, sometimes in complex and unexpected ways that involve struggle (e.g. Paula's expectation that lecturers understand the language differences, and Farzad's insistence he receive detailed feedback). Using the framework, we have accessed student interviews in a novel way and in doing so, we have in part responded to calls for research that identifies "students' local and multilingual contexts", personal histories and needs (Casanave 2012, p. 293) and "sensitive research tools" (Cotterall 2015, p. 360) when studying the identity work of doctoral students. 
We acknowledge that our interpretations are partial and are shaped by our own identities as academic writing teachers, multilingual writers, and supervisors. Nevertheless, we see value in seeking further understandings of identities as a way to disrupt perceptions of fixed categories and to prompt us to look beyond these to see more varied and less predictable or less essentialised identities and deficit perceptions of EAL HDR student writers. By approaching doctoral students' identities as "relational and socio-culturally emerging phenomen[a] in local discourse contexts of interaction" (Bucholtz \& Hall, 2005, pp. 585-586), we are able to look beyond fixed categories and reveal identities or subject positions that do not often or openly feature in institutional and public discourses about international doctoral education. The exposition of the emergent identity productions in moment-to-moment spoken interaction is a valuable first step in thinking about how they may be harnessed by various stakeholders including lecturers, academic writing teachers or supervisors and also institutional structures that govern graduate research in universities. Implications of the current study include the potential for broadening discussions around the writing processes to accommodate a focus on the quality of writer/teacher/supervisor interactions. This connects with recent research that explores how recognition of the multiple identities and roles of EAL HDR student writers can set the scene for engaging multi- or translingual academic writing pedagogies (e.g., Brinkschulte et al., 2018) and supervision pedagogies of intellectual equality (e.g., Singh \& Han, 2017).

The strong response to our research call by not only EAL HDR student writers, but also supervisors of such people, indicates the need for a space for more talk around aspects impacting on EAL HDR student writing. While it is impossible to fully understand students' backgrounds and identities, conscious attention to how they construct themselves and others in spoken interaction is a part of the process that can offer nuanced understandings of their multiple identities.

\section{Acknowledgments}

The authors would like to acknowledge the support of the students and supervisors who took part in these interviews. We also thank the two anonymous reviewers and the editors for their valuable feedback on earlier drafts of this paper. 


\section{References}

Ai, B. (2017). Constructing an academic identity in Australia: An autoethnographic narrative. Higher Education Research and Development, 36(6), 1095-1107. https://doi.org/10.1080/07294360.2017.1303459

Aitchison, C., Catterall, J., Ross, P., \& Burgin, S. (2012). "Tough love and tears": Learning doctoral writing in the sciences. Higher Education Research and Development, 31(4), 435-447. https://doi.org/10.1080/07294360.2011.559195

Badenhorst, C., Moloney, C., Rosales, J., Dyer, J., \& Ru, L. (2015). Beyond deficit: Graduate student research-writing pedagogies. Teaching in Higher Education, 20(1), 1-11. https://doi.org/10.1080/13562517.2014.945160

Botelho de Magalhães, M., Cotterall, S., \& Mideros, D. (2019). Identity, voice and agency in two EAL doctoral writing contexts. Journal of Second Language Writing, 43, 4-14. https://doi.org/10.1016/j.jslw.2018.05.001

Brinkschulte, M., Grieshammer, E., \& Stoian, M. (2018). Translingual academic writing at internationalised universities: Learning from scholars. Journal of Academic Writing, 8(2), 150-160. https://doi.org/10.18552/joaw.v8i2.460

Bucholtz, M., \& Hall, K. (2005). Identity and interaction: A sociocultural linguistic approach. Discourse Studies, 7(4-5), 585-614. https://doi:10.1177/1461445605054407

Canagarajah, A. S. (2015). "Blessed in my own way": Pedagogical affordances for dialogical voice construction in multilingual student writing. Journal of Second Language Writing, 27, 122-139. https://doi.org/10.1016/j.jslw.2014.09.001

Casanave, C. P. (2002). Writing games: Multicultural case studies of academic literacy practices in higher education. Lawrence Erlbaum Associates, Inc., Publishers.

Casanave, C. P. (2010). Taking risks?: A case study of three doctoral students writing qualitative dissertations at an American university in Japan. Journal of Second Language Writing, 19, 1-16. https://doi.org/10.1016/j.jslw.2009.12.002

Casanave, C. P. (2012). Controversies and change in how we view L2 writing in international contexts. In L. Alsagoff, S.L. Mackay, G. Hu, \& W.A. Renandya (Eds.), Principles and practices for teaching English as an international language (pp. 284-295). Routledge.

Chang, Y. J. (2011). Picking one's battles: NNES doctoral students' imagined communities and selections of investment. Journal of Language, Identity and Education, 10(4), 213-230. https://doi.org/10.1080/15348458.2011.598125

Cotterall, S. (2011). Doctoral students writing: Where's the pedagogy? Teaching in Higher Education, 16(4), 413-425. https://10.1080/13562517.2011.560381

Cotterall, S. (2013). More than just a brain: Emotions and the doctoral experience. Higher Education Research and Development, 32(2), 174-187. https://doi.org/10.1080/07294360.2012.680017

Cotterall, S. (2015). The rich get richer: International doctoral candidates and scholarly identity. Innovations in Education and Teaching International, 52(4), 360-370. https://doi.org/10.1080/14703297.2013.839124

Hyland, K. (2012). Disciplinary identities: Individuality and community in academic discourse. Cambridge University Press. 
Ingleton, C., \& Cadman, K. (2002). Silent issues for international postgraduate research students' emotion and agency in academic success. Australian Educational Researcher, 29(1), 93-114.

Ivanič, R. (1998). Writing and identity: The discoursal construction of identity in academic writing. John Benjamins.

Kamler, B., \& Thomson, P. (2006). Helping doctoral students write: Pedagogies for supervision. Routledge.

Koehne, N. (2005). (Re)construction: Ways international students talk about their identity. Australian Journal of Education, 49(1), 104-119. https://doi.org/10.1177/000494410504900107

Leki, I. (2006). "You cannot ignore": L2 graduate students' response to feedback. In K. Hyland \& F. Hyland (Eds.), Feedback in second language writing: contexts and issues (pp. 266-285). Cambridge University Press.

Manathunga, C. (2007). Intercultural postgraduate supervision: Ethnographic journeys of identity and power. In D. Palfreyman \& D. McBride (Eds.), Learning and Teaching Across Cultures in Higher Education (pp. 93-113). Palgrave Macmillan. https://doi.org/10.1057/9780230590427 6

Mango, O. (2012). Arab American women negotiating identities. International Multilingual Research Journal, 6(2), 83-103. https://doi.org/10.1080/19313152.2012.665823

Morton, J., Storch, N., \& Thompson, C. (2014). Feedback on writing in the supervision of postgraduate students: insights from the work of Vygotsky and Bakhtin. Journal of Academic Language \& Learning, 8(1), 24-36.

Phan, L. H. (2009). Strategic, passionate, but academic: Am I allowed in my writing? Journal of English for Academic Purposes, 8, 134-246. https://doi.org/10.1016/j.jeap.2008.09.003

Rajadurai, J. (2010). Speaking English and the Malay community: The struggle for participation and the negotiation of identities. Indonesia and the Malay World, 38(111), 289-301. https://doi.org/10.1080/15348451003704776

Shenk, P. S. (2007). "I'm Mexican, remember?" Constructing ethnic identities via authenticating discourse. Journal of Sociolinguistics, 11(2), 194-220. https://doi.org/10.1111/j.14679841.2007.00318.x

Singh, M., \& Han, J. (2017). Pedagogies for internationalising research education. Intellectual equality, theoretic-linguistic diversity and knowledge chuàngxīn. Palgrave Macmillan.

Soong, H., Tran, L. T., \& Hiep, P. H. (2015). Being and becoming an intercultural doctoral student: Reflective autobiographical narratives. Reflective Practice, 16(4), 435-448. https://doi.org/10.1080/14623943.2015.1023276

Starke-Meyerring, D., Paré, A., Sun, K. Y., \& El-Bezre, N. (2014). Probing normalized institutional discourses about writing: The case of the doctoral thesis. Journal of Academic Language and Learning, 8(2), A13-A27.

Tardy, C. (2005). Expressions of disciplinarity and individuality in a multimodal genre. Computers and Composition, 22(3), 319-336.

https://doi.org/10.1016/i.compcom.2005.05.004

Tardy, C. (2016). Voice and identity. In R.M. Manchón \& P.K. Matsuda (Eds.), Handbook of Second and Foreign Language Writing (pp. 349-363). de Gruyter. 
Thompson, C., Morton, J., \& N. Storch (2016). Becoming an applied linguist. The Australian Review of Applied Linguistics 39(2), 139-157. https://doi.org/10.1075/aral.39.2.03tho

Tran, L., Nguyen, L., \& Green, W. (2017). Enhancing the experience and outcomes of international higher degree research candidates: Reciprocal intercultural supervision. International Research Association of Australia: Research Digest, 12. 